\title{
Existing public health surveillance systems for mental health in China
}

\author{
Wei Zhou and Shuiyuan Xiao*
}

\begin{abstract}
Mental health is a challenging public health issue worldwide and surveillance is crucial for it. However, mental health surveillance has not been developed until recently in certain developed countries; many other countries, especially developing countries, have poor or even no health information systems. This paper presents surveillance related to mental health in China, a developing country with a large population of patients with mental disorders. Detailed information of seven relevant surveillance systems is introduced respectively. From the perspective of utilization, problems including accessibility, comprehensiveness and data quality are discussed. Suggestions for future development are proposed.
\end{abstract}

Keywords: Public health surveillance, Mental health, China, Review

\section{Introduction}

Mental illness is a worldwide challenge in public health. In 2010, mental illness accounted for an estimated $7.4 \%$ of the world's measured in disability-adjusted life years (DALYs), and the years lived with disability (YLDs) resulting from mental and behavioral disorders contributed to 22.7\%, the highest YLDs among all diseases [1-3]. Despite the significantly negative impact on people's life, $35 \%$ to $50 \%$ of people with severe mental disorders in highincome countries do not receive needed treatment, and the rate can increase to $75 \%$ to $85 \%$ in low- and middleincome countries [4].

Surveillance is crucial for mental health, as it is the foundation for well-informed and evidence-based decisionmaking on disease control and prevention, services provision and delivery [5]. WHO's Comprehensive Mental Health Action Plan 2013-2020 also sets strengthening mental health information system as one of the four objectives [6].

A majority of countries collect data on the number of people treated and service user diagnosis [7]; however, developing systematic surveillance is a recent trend. For example, the collation of existing data as the first step toward developing mental health surveillance was proposed in Canada in 1999 [8]; the Mental health Information and

\footnotetext{
* Correspondence: xiaosy@csu.edu.cn

Department of Social Medicine and Health Management, School of Public Health, Central South University, 110 Xiangya Road, Changsha 410078, China
}

Determinants for the Europe Level Project proposed to develop European mental health information systems in 2006 [9]; for U.S. currently with a relatively mature mental health surveillance network, the government has begun infrastructure construction for establishing an ongoing system for mental health surveillance since 1999 [10]. Despite the short history, mental health surveillance in countries like U.S., U.K., Australia has developed rich content, which can be categorized into four domains: the first is surveillance on mental health problems, including the diagnosis of mental disorders and a range of manifestation of alteration in thinking, mood, behavior and associated with distress that correspond with clinical disorder; the second category is risk factors, like stressors, social support, social and economic status, and birth defects; the third and forth categories are about the mental health services and rights protection for the patients. The surveillance data of the above countries are widely used in government decisionmaking and academic research [11-15].

Unlike the above countries which develop mental health surveillance on well-developed public health surveillance, many other countries, especially developing countries, have poor or even no health information systems, let alone mental health information systems [7]. This paper will focus on the case of China, a large developing country where there are estimated 16 million patients with psychotic disorders, based on a recent epidemiological survey conducted in four provinces [16]. Existing problems of 
Chinese surveillance related to mental health are discussed from the perspective of data utilization and suggestions for future development are proposed accordingly.

\section{Surveillance systems and surveys relevant to mental health in China}

After the founding of the People's Republic of China in 1949, the government first established the Notifiable Infectious Disease Reporting System as a start of disease surveillance. After decades of development, disease surveillance has gradually extended to be public health surveillance with a wider scope, covering not only infectious diseases, but also some non-communicable diseases and health-related factors and events [17]. In 2012, the newlypassed Mental Health Law for the first time explicitly stipulated that a mental health surveillance network should be established (article 24) and that mental health work plans should be based on surveillance results (article 60).

Although China has a basic knowledge of mental health prevalence and mental health services through epidemiological surveys, the National System of Basic Information Collection and Analysis for Psychoses is the only mentalhealth-themed surveillance system in China. Certain data on mental health are collected through other public health surveillance systems (Table 1) organized by government departments like centers for disease control and prevention (CDCs), the Ministry of Health (MOH [now the National Health and Family Planning Commission]) or provincial departments of health, and statistical departments. Brief introductions for each system are listed as follows.

\section{National system of basic information collection and analysis for psychoses}

In December 2004, China initiated the National Continuing Management and Intervention Programme for Psychoses (also named 686 Programme), as a response to the Chinese government's concern on social harmony and stability [18]. One of the program tasks was to register patients diagnosed with 4 types of psychoses, which are schizophrenia, bipolar disorder, delusional disorder, and schizoaffective disorder. One urban and one rural area in each of the 30 provinces in China were selected as pilot sites for this program, and a population of 43 million was covered. By June 2011, the program had developed and been expanded to cover a population of 330 million in 680 urban districts/counties of 160 cities [18,19].

In August 2011, the online system titled National System of Basic Information Collection and Analysis for Psychoses was released nationwide (http://1.202.129.170:90/mh/). The system operated by $\mathrm{CDC}$, has extended the reporting scope to 6 types of severe mental illnesses: schizophrenia, schizoaffective disorder, bipolar disorder, delusional disorder, psychotic disorder due to epilepsy and mental retardation. Local medical units across China, including mental hospitals, general hospitals with mental health units, community health centers and village clinics, are responsible for case reporting. The system mainly collects 4 categories of information: 1) demographics of patients; 2) management information, including ID number, guardian contacts, informed consent on management; 3 ) information related to disease and care, including family history of mental disorders, diagnosis, the time for the first disease attack,

Table 1 Public health surveillance systems that collect data on mental health

\begin{tabular}{|c|c|c|c|}
\hline Category & Name and main sponsor & Mental health topics & Data release \\
\hline $\begin{array}{l}\text { Mental-health-themed } \\
\text { surveillance }\end{array}$ & $\begin{array}{l}\text { National System of Basic Information } \\
\text { Collection and Analysis for } \\
\text { Psychoses, China CDC }\end{array}$ & $\begin{array}{l}\text { Diagnosis of mental illnesses, family } \\
\text { history of mental disorders, medication }\end{array}$ & No data release by so far \\
\hline \multirow{6}{*}{$\begin{array}{l}\text { Public health surveillance } \\
\text { collecting data on } \\
\text { mental health }\end{array}$} & BRFSS, China CDC & $\begin{array}{l}\text { Health status, health care and services, } \\
\text { tobacco use, alcohol consumption }\end{array}$ & No regular data releasing \\
\hline & $\begin{array}{l}\text { National Injury Surveillance } \\
\text { System, China CDC }\end{array}$ & $\begin{array}{l}\text { Activity when injury happening; cause } \\
\text { of injury (including intentional), } \\
\text { nature and severity of injury }\end{array}$ & $\begin{array}{l}\text { Detailed statistics published through } \\
\text { book series: Dataset of National Injury } \\
\text { Hospital Surveillance (2007-2012) }\end{array}$ \\
\hline & $\mathrm{MOH}-\mathrm{VR}$, China $\mathrm{MOH}$ & $\begin{array}{l}\text { Facts and causes of the } \\
\text { death (including suicide) }\end{array}$ & $\begin{array}{l}\text { Data released within health } \\
\text { administrative departments }\end{array}$ \\
\hline & NDSP-MR, China CDC & $\begin{array}{l}\text { Facts and causes of the } \\
\text { death (including suicide) }\end{array}$ & $\begin{array}{l}\text { Detailed statistics published through } \\
\text { book series: Dataset of Mortality } \\
\text { Registration in NDSP (2004-2011) }\end{array}$ \\
\hline & $\begin{array}{l}\text { Working System for National } \\
\text { Health Statistics, China } \mathrm{MOH}\end{array}$ & $\begin{array}{l}\text { Mental health resources } \\
\text { (e.g. the numbers of institutions, } \\
\text { beds and staff), service utilization }\end{array}$ & $\begin{array}{l}\text { Yearbook of China Health } \\
\text { Statistics published annually }\end{array}$ \\
\hline & $\begin{array}{l}\text { Civil Affairs Statistical Information } \\
\text { Management System, China } \\
\text { Ministry of Civil Affairs }\end{array}$ & $\begin{array}{l}\text { Mental health services } \\
\text { within civil affairs system }\end{array}$ & $\begin{array}{l}\text { Annual reports (1986-2012) available } \\
\text { at http://cws.mca.gov.cn/article/tjbg/ }\end{array}$ \\
\hline
\end{tabular}


medication; 4) other information, including financial situation, troubles/accidents conducted and assessment on the risk of violence [20].

\section{Behavioral Risk Factor Surveillance System (BRFSS)}

The system was established in 1996 based on a World Bank project in China, and now China CDC is responsible for its operation. The system targets on urban residents aged from 16 to 69 and collects data through monthly household surveys. It covers about 60 districts and counties located in 7 cities and 1 province and a population of 25 million [17]. Surveys consist of two parts: 1) core questions designed by China CDC and asked in all surveillance districts; 2) questions added by individual cities. 12 sections are included in core questions; they are demographics, health status, health care and services, tobacco use, alcohol consumption, awareness of controlling high blood pressure, awareness of controlling hyperlipidemia, exercise (physical activity), healthy diet, maternal health, accidental injury, knowledge and actions of sexually transmitted diseases (STD) and AIDS. In 1996, approximately 4800 interviews were completed in every city/ province as baseline. From 2007 to 2001, there were approximately 4800 completed interviews per year in every city/province [21].

\section{National injury surveillance system}

The system has been operated by China CDC since January 2006. It is sentinel surveillance based on hospital emergency departments [22]. The system samples 43 counties/cities/districts as surveillance sites across China, with 23 in rural areas and 20 in cities. 127 hospitals are included in the system. 3 categories of information are collected through paper reporting cards filled by hospitals: 1) general information of the patient, including name, age, education level, occupation; 2) general information of the injury, including the time, place and reason of the injury, the activity when the injury occurring, intentional or not, and the time of seeing a doctor; 3) clinical information of the injury, including the nature and part of the injury, severity, and clinical diagnosis and outcome. In 2010, the annual number of reporting cards exceeded 620,000 [23].

\section{Mortality registration and surveillance}

Conventional mortality registration and surveillance in China is fulfilled through the Vital Registration System administrated by $\mathrm{MOH}$ (MOH-VR) and Mortality Registration in the National Disease Surveillance Point (NDSP) System operated by CDC (NDSP-MR) [24].

MOH-VR was established in 1987. The standard reporting document is a death certificate issued by a hospital, which contains personal information of the dead, the fact (e.g. death sites) and cause of the death (e.g. diagnosis of the fatal disease). In 2004, online reporting from medical institutions at county or above level across China was employed and the Vital Registration Information System was set under China Information System for Disease Control and Prevention (www.cdpc.chinacdc.cn/). This promoted the increase of reported deaths by year. In 2006, over 930,000 deaths were reported via the online system, accounting for $12.83 \%$ of the total deaths in China. By 2007 , the online reporting has covered nearly $80 \%$ counties/city districts [25].

The NDSP System sets surveillance points according to a multistage cluster probability sampling with stratification at three levels [24]. By 2006, the system has developed 161 surveillance points and covered over 73 million population [26]. Initially, the NDSP system was designed to collect data on births, causes of death, and the incidence of infectious diseases. Since 1990, the system has covered mortality of 35 notifiable diseases and gradually expanded to deaths of other causes [24]. Similar to MOH-VR, NDSPMR also depends on death certificates for information collection [27].

\section{Working system for national health statistics}

The primary tasks of the system include: 1) collecting information regarding the input, allocation and utilization of health resources, the quality and efficiency of health services, and the health status of the population; 2) reporting statistical data and analysis; 3) providing statistical consulting and supervision. The whole-process work is administrated by $\mathrm{MOH}$. Medical units at all levels, including metal health institutions, are required to report to local administrative departments of health their health data, including the number of hospital beds and medical staff, the income and expenditure, the person-time of service utilization, and institutions' ownership [28]. In 2007, the online reporting system for national health statistics was put in use (http://tjbb.zjwst.gov.cn:8080/irpt/i/oem/wsb/ login.jsp).

\section{Civil affairs statistical information management system}

In order to monitor the work progress of civil affairs, the Ministry of Civil Affairs established the Work System of Civil Affairs Statistics in 1987. The current information system is functioned with data collection, reporting and analysis. The system can provide data regarding services for the intellectual disability and mental illnesses administrated by departments of civil affairs, including the number of institutions, beds and persons being served [29].

\section{Other surveillance systems potentially relevant to mental health}

U.S. CDC categorizes infectious disease within mental health information [30] and some infectious diseases, like Japanese encephalitis, meningococcal meningitis, rabies, HIV/AIDS and some STDs, can damage the neurologic 
system or may lead to complications or sequel of mental disorders. Certain birth defects (e.g. meningitis, mongolian idiocy, Down's syndrome and defects of neurologic-system damage), maternal deaths and causes, social support in early childhood are related to mental health. Therefore, the Infectious Disease Reporting System and the Specific Infectious Disease Management Information System both within China Information System for Disease Control and Prevention, the Information Reporting System of HIV/ AIDS, and the Maternal and Child Health Surveillance, also possibly provide information on mental health.

\section{Problems to be addressed}

As ultimate purposes of surveillance are to inform government decision-making and to facilitate academic research, problems of the aforementioned surveillance are proposed mainly from the perspective of utilization.

\section{Accessibility of data}

The aforementioned surveillance systems are all established and operated by government departments and their management documents explicitly state that data are provided as evidence for health administration and decision making $[22,25,27]$. However, information sharing within the health sector and between departments is limited. Longitudinally, the authorization on data access of surveillance organizations is decided by their administrative levels [20]. $\mathrm{MOH}$ and China CDC have full access to data across China. A municipal CDC can only view the data of its own city, rather than the whole database of its province. Horizontally, information sharing between different surveillance systems is constrained by the incompatibility of their independent software and hardware [31]. The internal division of duties in the surveillance organizations further reinforces the information blocking. For example, in CDCs, the work related to mental health is included in the division of chronic diseases, which is independent from the division of infectious diseases. As a result, though some infectious diseases are the risk factors of mental disorders, their surveillance are not listed and used in mental health surveillance.

As is presented in Table 1, no data release of BRFSS, $\mathrm{MOH}-\mathrm{VR}$, and National System of Basic Information Collection and Analysis for Psychoses have been found by so far, which account for over $1 / 3$ of the listed systems. For the rest ones, summary reports at national level are released to the public, but in variable details and at different time intervals. For example, injury surveillance, NDSP-MR and Working System for National Health Statistics publish detailed statistics of each item on the reporting form, as well as the name list of surveillance points, relevant work manuals, procedures and standards, and government documents in books. Main findings of the Civil Affairs Statistical Information
Management System are released through a summary form by year or annual reports.

Even though, it is inconvenient for the academic circle to obtain raw data without summary and analysis/statistical processing. Papers based on raw data of the above systems were mainly published by local surveillance staff using data of their regions [32-34].

\section{Comprehensiveness of data scope}

Compared with the summarized categorization of surveillance content worldwide, surveillance on rights protection is still missing in China, partly because the Mental Health Law passed just a short time ago and some details of implementation are under discussion.

The surveillance categories of mental health problems are limited. First, The National System of Basic Information Collection and Analysis for Psychoses currently only focuses on six severe mental illnesses and other systems only collect data on suicides, intentional injuries, tobacco use and alcohol consumption. Mental disorders commonly found in populations, like depression and anxiety, are not covered and surveillance on substance-related and addictive disorders should go beyond tobacco or alcohol consumption. Second, China mainly focuses on the diagnosed mental disorders and behaviors conducted. However, symptoms of psychological distress without diagnosis, emotional problems (like depression and anxiety) at the screening points, and suicide ideation have not included yet. Third, many surveillance systems in China collect information through self-designed reporting forms, rather than screening instruments, like World Health Organization Disability Assessment Schedule (WHODAS) and AUDADIS-IV (Alcohol Use Disorder and Associated Disabilities Interview Schedule-IV) [11]. The limited number of items in the reporting forms leads to the incomprehensiveness.

In terms of risk factors, unlike US, Europe and Australia including factors like stress, poverty and inequality and poor education in mental health surveillance $[12,14,35]$, current surveillance in China mainly includes the biological ones, like damages of neurological system and genetic diseases. Even though surveillance systems containing these biological risk factors, like the Maternal and Child Health Surveillance and the Infectious Disease Surveillance, have not been widely accepted as and used for mental health surveillance in China.

\section{Quality of data}

Quality-control procedures are designed for most surveillance systems. The frequently-adopted methods include self-check, cross check between organizations at the same level and regular check from upper-level organization on the timeliness, completeness and accuracy of data and automatic logical correction by reporting systems $[20,24]$. 
In attempt to check the results of quality control for each of the discussed surveillance systems, we identify evaluation studies on completeness, accuracy and underreporting through the following procedures. We adopted search combinations of "names of surveillance systems" and "quality", and retrieved academic papers through abstract search in China National Knowledge Infrastructure in August 2014, which has over 90\% of China knowledge resources with the widest in title and type coverage and the deepest in year coverage in China. One quantitative evaluation paper was identified for each surveillance under the principles that the studies at national level are selected prior to the ones at provincial or lower levels and that the most recently published studies are selected when there are more than one studies at the same level.

As Table 2 shows that surveillance systems have very limited or even no evaluation studies, which can be partly attributed to the restriction on data access. According to the identified studies, many surveillance systems are underperformed, even only judging from the completeness and accuracy of data, as well as their underreporting rates (Table 2). Factors including the lack of professionals, inadequate training for data reporters, and poor hardware for online reporting in certain areas are proposed as explanations $[31,36]$. Repeated surveillance from different systems on certain themes, like the mortality surveillance [31], increases the workload of first-line medical staff and data collectors, which is also negative for surveillance quality.

\section{Suggestions for future development}

For the future development of mental health surveillance, a comprehensive surveillance with a full coverage of mental-health-related events is suggested. On the one hand, surveillance indicators should be enriched through expert consultancy and adopting international screening instruments. On the other hand, surveillance scope should be extended to include more categories of mental health problems like depression and substance-related and addictive disorder. Multiple sources of risk factors and law implementation should also be covered. Streamlining the surveillance systems discussed will be a helpful way of expanding surveillance scope.

Second, the government must make the data more accessible for clinical practices, research and evidencebased decision making at all government levels. Publishing surveillance results regularly should become a routine for all surveillance systems. Application procedures for accessing data should be operable. Provisions on privacy protection should also be developed and applied equally to all individual or department data users.

Third, adequate resources for surveillance and implemented evaluations mechanism are keys to quality improvement. To guarantee quality and appropriate collection of data, adequate inputs of funding and staff with necessary training should be provided as a precondition. Systematic and scientific evaluations under published criteria and frameworks should be conducted and guide continuous quality-improvement measures.

\section{Conclusion}

The existing public health surveillance networks lay a good foundation for its future development. Problems in the aspects of data accessibility, comprehensiveness of data scope and quality of data should be solved for better utilization of surveillance in both government decision making and academic research. Promoted by the requirement by Mental Health Law and devoted efforts for improvement, mental health surveillance will be well developed in China.

Table 2 Evaluation studies on data quality of discussed surveillance systems

\begin{tabular}{|c|c|c|c|c|c|c|}
\hline \multirow[t]{2}{*}{ Category } & \multirow[t]{2}{*}{ Surveillance systems } & \multirow{2}{*}{$\begin{array}{l}\text { Number of } \\
\text { the retrieved }\end{array}$} & \multirow[t]{2}{*}{ Identified articles } & \multicolumn{3}{|c|}{ Evaluation indicators } \\
\hline & & & & $\begin{array}{l}\text { Underreporting } \\
\text { rate }\end{array}$ & $\begin{array}{l}\text { Completeness } \\
\text { rate }\end{array}$ & $\begin{array}{l}\text { Accuracy } \\
\text { rate }\end{array}$ \\
\hline $\begin{array}{l}\text { Mental-health-themed } \\
\text { surveillance }\end{array}$ & $\begin{array}{l}\text { National System of Basic } \\
\text { Information Collection } \\
\text { and Analysis for Psychoses }\end{array}$ & 1 & Reference [37] (City) & - & $83.0 \%$ & $52.8 \%$ \\
\hline \multirow{6}{*}{$\begin{array}{l}\text { Public health surveillance } \\
\text { collecting data on } \\
\text { mental health }\end{array}$} & BRFSS & 5 & - & - & - & - \\
\hline & $\begin{array}{l}\text { National Injury } \\
\text { Surveillance System }\end{array}$ & 37 & Reference [38] (City) & $10.65 \%$ & $89.89 \%$ & - \\
\hline & $\mathrm{MOH}-\mathrm{VR}$ & 20 & Reference [39] (Provincial) & $72.67 \%$ & - & $91.41 \%$ \\
\hline & NDSP-MR & 81 & Reference [40] (Provincial) & $14.44 \%$ & $85.11 \%$ & - \\
\hline & $\begin{array}{l}\text { Working System for } \\
\text { National Health Statistics }\end{array}$ & 17 & - & - & - & - \\
\hline & $\begin{array}{l}\text { Civil Affairs Statistical Information } \\
\text { Management System }\end{array}$ & 0 & - & - & - & - \\
\hline
\end{tabular}




\section{Abbreviations}

BRFSS: Behavioral risk factor surveillance system; CDC: Center for disease control and prevention; $\mathrm{MOH}$ : Ministry of health; $\mathrm{MOH}-\mathrm{VR}$ : Vital registration system administrated by MOH; NDSP System: National disease surveillance point system; NDSP-MR: Mortality registration in the NDSP System; STD: Sexually transmitted disease.

\section{Competing interests}

The authors declare that they have no competing interests.

\section{Authors' contributions}

WZ participated in the study design, acquired the data and drafted the manuscript. SYX conceived of the study, participated in its design and revised the manuscript critically. All authors read and approved the final manuscript.

\section{Acknowledgements}

We acknowledge financial support by China Medical Board (CMB-11-058) to SYX and Hunan Provincial Innovation Foundation for Postgraduate (CX2013B097) to WZ.

\section{Received: 6 November 2014 Accepted: 19 December 2014} Published: 5 January 2015

\section{References}

1. Murray CJ, Vos T, Lozano R, Naghavi M, Flaxman AD, Michaud C, et al, Disability-adjusted life years (DALYs) for 291 diseases and injuries in 21 regions, 1990-2010: a systematic analysis for the Global Burden of Disease Study 2010. Lancet. 2012;380:2197-223.

2. Vos T, Flaxman AD, Naghavi M, Lozano R, Michaud C, Ezzati M, et al. Years lived with disability (YLDs) for 1160 sequelae of 289 diseases and injuries 1990-2010: a systematic analysis for the Global Burden of Disease Study 2010. Lancet. 2012:380:2163-96.

3. Becker AE, Kleinman A. Mental health and the global agenda. N Engl J Med. 2013;369:66-73.

4. WHO World Mental Health Survey Consortium. Prevalence, severity, and unmet need for treatment of mental disorders in the world health organization world mental health surveys. JAMA. 2004;291(21):2581-90.

5. WHO. WHO mental health policy and service guidance package: mental health information systems. Geneva: World Health Organization; 2005.

6. WHO. Comprehensive mental health action plan 2013-2020. Resolution WHA66/8; [http://www.who.int/mental_health/action_plan_2013/en/]

7. WHO. Mental health atlas 2011. Geneva: World Health Organization; 2011.

8. Health Canada. A report on mental illnesses in Canada. Ottawa; 2002.

9. Korkeila J, Tuomi-Nikula A, Gissler M, Wahlbeck K, Lehtinen V, Lavikainen J. Introduction. In: Lavikainen J, Fryer T, Lehtinen V, editors. Improving mental health information in Europe: proposal of the MINDFUL project. Helsinki: Stakes and European Union; 2006. p. 11-21 [http://www.julkari.fi/bitstream/ handle/10024/77861/Mindful_verkkoversio.pdf?sequence=1]

10. Freeman EJ, Colpe LJ, Strine TW, Satvinder D, cGuire LC, Elam-Evans LD, et al. Public health surveillance for mental health. Prev Chronic Dis. 2010;7(1):A17.

11. SAMHSA, RTI International. Comparison of NSDUH mental health data and methods with other data sources. CBHSQ data review. 2012.

12. Tomlin $\mathrm{S}$, Joyce $\mathrm{S}$. The health and wellbeing of children in Western Australia in 2012, overview and trends. Western Australia: Department of Health; 2013 [http://www.health.wa.gov.au/publications/documents/ HWSS Child_Overview_and Trends 2012.pdf]

13. UK Care Quality Commission. Monitoring the mental health act in 2010/11. UK; 2011.

14. U.S. CDC. Mental illness surveillance among adults in the United States. Morb Mortal Wkly Rep. 2011;60(Suppl):1-29.

15. Zhou W, Xiao SY. The development of mental health surveillance outside China: introduction. Chin Ment Health J. 2014;28(1):3-7 (In Chinese).

16. Phillips MR, Zhang J, Shi Q, Song Z, Ding Z, Pang S, et al. Prevalence, treatment, and associated disability of mental disorders in four provinces in China during 2001-05: an epidemiological survey. Lancet. 2009:373:2041-53.

17. Zhai SH. Public health surveillance. In: Tan HZ, editor. Modern epidemiology. 2nd ed. Beijing: People's Medical Publishing House; 2008. p. 313-22 (In Chinese).

18. Liu J, Ma H, He YL, Xie B, Xu YF, Tang HY, et al. Mental health system in China: history, recent service reform and future challenges. World Psychiatry. 2011;10:210-6.
19. Ma H, Liu J, He YL, Xie B, Xu YF, Hao W, et al. An important pathway of mental health service reform in China: introduction of 686 Programme. Chin Ment Health J. 2011;25(10):725-8 (In Chinese).

20. General Office of the Ministry of Health. Notice on starting national system of basic information collection and analysis for psychoses. 2011 [http://www.moh. gov.cn/jkj/s5888/201108/ccf6555cfe6543b8816ee507fdecf93a.shtml]

21. Gan ZG, Zhuo JT. An overview of Chinese BRFSS. Mod Prev Med. 2003;30 (4):550-2 (In Chinese).

22. China MOH. Notice on conducting national injury surveillance. 2005 (In Chinese).

23. Duan $L L$, Wu F, Yang GH, Deng X, Jiang W, Wang Y, et al. The development of Chinese national injury surveillance system. Chin J Health Educ. 2012;28 (4):338-41 (In Chinese).

24. Yang GH, Hu JP, Rao KQ, Ma J, Rao C, Lopez AD. Mortality registration and surveillance in China: history, current situation and challenges. Popul Health Metrics. 2005;3(3):1-9.

25. China CDC. Work specifications for national mortality registration information online reporting (draft). 2007 (In Chinese).

26. China CDC. Dataset of mortality registration in NDSP (2006). Beijing: Military Medical Science Publishing House; 2010 (In Chinese).

27. China CDC. Work specifications on mortality registration in the NDSP system (Trial). 2005 (In Chinese).

28. China MOH. Measure for the management of national health statistics. 1999 (In Chinese).

29. China Ministry of Civil Affairs. Statistical report of the development of social services in 2011. 2011 (In Chinese).

30. U.S. CDC. Infectious disease, CDC mental health information. [http://www. cdc.gov/mentalhealth/information/inf-diseases.htm]

31. Yang C. The present situation of disease surveillance in China. Shanghai J Prev Med. 2012;24(6):336-42 (In Chinese).

32. Li QJ, Huang $X Y$, Wen $H$, Liang $X Q$, Lei $L, W u J$. Retrospective analysis of treatment effectiveness among patients in Mianyang Municipality enrolled in the national community management program for schizophrenia. Shanghai Arch Psychiatry. 2012;24:131-9.

33. He AL. Analysis on epidemiological characteristics and related factors of community psychoses. China Health Care Nutr. 2012;11:4271-3 (in Chinese).

34. Xu F, He J, Mei D, Yuan X. Data analysis of injury cases in surveillance hospital in Dalian City in 2009. J Dis Monit Control. 2011;5(10):589-91 (In Chinese).

35. Wahlbeck K. Mental health in EU health monitoring systems. In: Lavikainen J, Fryer T, Lehtinen $V$, editors. Improving mental health information in Europe: proposal of the MINDFUL project. Helsinki: Stakes and European Union; 2006. p. 117-27 [http://www.julkari.fi/bitstream/handle/10024/77861/ Mindful_verkkoversio.pdf? sequence $=1]$

36. Liu XY, Li LP. Influencing factors of the quality of disease surveillance. Dis Surveill. 2010;23(4):199-203 (In Chinese).

37. Luo BA, Xiao SY, Fu WB, Li XP. Quality evaluation on national system of basic information collection and analysis for psychoses. Chin J Public Health. 2014:30:958-9 (in Chinese).

38. Wu SF, Chen Q, Li DY, Liang XD, Chen GR, Chen HJ, et al. Analysis of quality control of injury surveillance in Zhuihai in 2006. The 8th Guangdong, Hong Kong, Macao and Taiwan Academic Conference of Preventive Medicine. Zhuhai; 2008.

39. Xu XJ, Xu YJ, Cai QM, Song XL, Zhou SE, Meng RL, et al. Quality analysis of death cause reports in medical institutions in Guangdong, 2005-2012. South China J Prev Med. 2013;39(3):22-7 (In Chinese).

40. Xu XJ, Xu YJ, Cai QM, Song XL, Meng RL, Xu HF, et al. Death cause underreporting through disease surveillance system in Guangdong, 2009-2011. Dis Surveill. 2013;28(7):570-4.

doi:10.1186/1752-4458-9-3

Cite this article as: Zhou and Xiao: Existing public health surveillance systems for mental health in China. International Journal of Mental Health Systems 2015 9:3. 